\title{
Experimental Study of Boundary Layer Flow Control Using an Array of Ramp-Shaped Vortex Generators
}

Stefanie M. Hirt, Khairul B.M.Q. Zaman, and Timothy J. Bencic Glenn Research Center, Cleveland, Ohio 


\section{NASA STI Program . . . in Profile}

Since its founding, NASA has been dedicated to the advancement of aeronautics and space science. The NASA Scientific and Technical Information (STI) program plays a key part in helping NASA maintain this important role.

The NASA STI Program operates under the auspices of the Agency Chief Information Officer. It collects, organizes, provides for archiving, and disseminates NASA's STI. The NASA STI program provides access to the NASA Aeronautics and Space Database and its public interface, the NASA Technical Reports Server, thus providing one of the largest collections of aeronautical and space science STI in the world. Results are published in both non-NASA channels and by NASA in the NASA STI Report Series, which includes the following report types:

- TECHNICAL PUBLICATION. Reports of completed research or a major significant phase of research that present the results of NASA programs and include extensive data or theoretical analysis. Includes compilations of significant scientific and technical data and information deemed to be of continuing reference value. NASA counterpart of peer-reviewed formal professional papers but has less stringent limitations on manuscript length and extent of graphic presentations.

- TECHNICAL MEMORANDUM. Scientific and technical findings that are preliminary or of specialized interest, e.g., quick release reports, working papers, and bibliographies that contain minimal annotation. Does not contain extensive analysis.

- CONTRACTOR REPORT. Scientific and technical findings by NASA-sponsored contractors and grantees.
- CONFERENCE PUBLICATION. Collected papers from scientific and technical conferences, symposia, seminars, or other meetings sponsored or cosponsored by NASA.

- SPECIAL PUBLICATION. Scientific, technical, or historical information from NASA programs, projects, and missions, often concerned with subjects having substantial public interest.

- TECHNICAL TRANSLATION. Englishlanguage translations of foreign scientific and technical material pertinent to NASA's mission.

Specialized services also include creating custom thesauri, building customized databases, organizing and publishing research results.

For more information about the NASA STI program, see the following:

- Access the NASA STI program home page at http://www.sti.nasa.gov

- E-mail your question via the Internet to help@ sti.nasa.gov

- Fax your question to the NASA STI Help Desk at $443-757-5803$

- Telephone the NASA STI Help Desk at 443-757-5802

- Write to: NASA Center for AeroSpace Information (CASI) 7115 Standard Drive Hanover, MD 21076-1320 


\section{Experimental Study of Boundary Layer Flow Control Using an Array of Ramp-Shaped Vortex Generators}

Stefanie M. Hirt, Khairul B.M.Q. Zaman, and Timothy J. Bencic Glenn Research Center, Cleveland, Ohio

Prepared for the

50th Aerospace Sciences Meeting

sponsored by the American Institute of Aeronautics and Astronautics

Nashville, Tennessee, January 9-12, 2012

National Aeronautics and

Space Administration

Glenn Research Center

Cleveland, Ohio 44135 


\section{Acknowledgments}

The authors are grateful to Michelle Clem for help with the flow visualization experiment. The Subsonic Fixed Wing Project (SFW) of the NASA Fundamental Aeronautics Program supported this work.

Trade names and trademarks are used in this report for identification only. Their usage does not constitute an official endorsement, either expressed or implied, by the National Aeronautics and Space Administration.

This work was sponsored by the Fundamental Aeronautics Program at the NASA Glenn Research Center.

Level of Review: This material has been technically reviewed by technical management.

Available from

NASA Center for Aerospace Information 7115 Standard Drive

Hanover, MD 21076-1320
National Technical Information Service 5301 Shawnee Road Alexandria, VA 22312 


\title{
Experimental Study of Boundary Layer Flow Control Using an Array of Ramp-Shaped Vortex Generators
}

\author{
Stefanie M. Hirt, Khairul B.M.Q. Zaman, and Timothy J. Bencic \\ National Aeronautics and Space Administration \\ Glenn Research Center \\ Cleveland, Ohio 44135
}

\begin{abstract}
The objective of this study was to obtain a database on the flowfield past an array of vortex generators (VGs) in a turbulent boundary layer. All testing was carried out in a low speed wind tunnel with a flow velocity of $29 \mathrm{ft} / \mathrm{sec}$, giving a Reynolds number of 17,500 based on the width of the VG. The flowfield generated by an array of five ramp-shaped vortex generators was examined with hot wire anemometry and smoke flow visualization. The magnitude and extent of the velocity increase near the wall, the penetration of the velocity deficit into the core flow, and the peak streamwise vorticity are examined. Influence of various parameters on the effectiveness of the array is considered on the basis of the ability to pull high momentum fluid into the near wall region.
\end{abstract}

\section{Nomenclature}

$\begin{array}{ll}c & \text { Ramp chord length } \\ h & \text { Ramp height } \\ s & \text { Ramp spacing } \\ u & \text { Turbulence intensity in streamwise direction } \\ U & \text { Local streamwise mean velocity } \\ U_{\infty} & \text { Freestream velocity } \\ w & \text { Ramp width } \\ x & \text { Cartesian coordinate in streamwise direction (Fig. 1) } \\ y & \text { Cartesian coordinate in normal direction (Fig. 1) } \\ y_{\max } & \text { Vortex penetration } \\ z & \text { Cartesian coordinate in spanwise direction (Fig. 1) } \\ \delta & \text { Boundary-layer thickness } \\ \delta_{2} & \text { Boundary-layer momentum thickness } \\ \Delta U & \text { Velocity difference due to vortex generators, }\left(U_{\text {ramps }}-U_{\text {no ramps }}\right) / U_{\infty} \\ \omega_{\mathrm{x}} & \text { Streamwise vorticity }\end{array}$

\section{Introduction}

Vortex generators (VGs) have been effectively used to control boundary layer separation and reattachment in flows with adverse pressure gradients (Ref. 1), such as on wings and in internally diffusing flows as well as supersonic flows involving shocks. The VGs energize the flow in the near-wall region by mixing the higher momentum flow from the outer portion of the boundary layer and the core flow with the flow near the wall. This creates an increase in the near-wall velocity at the cost of creating a deficit farther from the wall. The increased streamwise velocity near the wall increases the resistance of the flow to separation. 
Recently the structural advantages of devices such as ramps, split ramps, and doublets that create a pair of counter-rotating streamwise vortices have generated interest in the use of those devices (Refs. 2 to 4). However, the interaction of the upwash region of the counter-rotating vortices causes the vortex pair to lift off the wall. This liftoff decreases the streamwise range of effectiveness of the devices by limiting the distance over which the vortices are close enough to the wall to effectively energize the flow.

The ramp-shaped VGs, described further in the following, offers an added advantage of easy fabrication. Previous studies have looked at the effect of varying the ramp geometries, including spacing, height, chord length, and ramp angles, on resulting boundary layer characteristics using measurements primarily with Pitot probes (Ref. 5). A large scale inlet study (Ref. 6) tested various VGs including the ramps for shock-induced boundary layer separation as well as control of secondary flow. The choice of the VGs in the latter experiment was based on CFD analysis and design principles for traditional VGs. However, questions remained on the optimum choice of the VG array parameters.

This prompted the current low-speed wind tunnel experiment that focuses on the impact of the spacing of the ramp-shaped VGs on the flow downstream based on detailed measurements of flow properties. Hot-wire anemometry is used to map the velocity, turbulence intensity, and vorticity in crossflow planes. Comparisons are made for several spacings on vortex penetration into the core flow, peak vorticity, and the magnitude of the velocity increase in the near-wall region.

\section{Experimental Setup}

The experimental setup is shown in Figure 1. An array of five ramp-shaped vortex generators was centered on the bottom wall of the test section. The figure also shows the location of a 'smoke plate' for introducing smoke into the boundary layer for flow visualization as well as the coordinate system. The picture in Figure 1(b) shows the hot-wire probes mounted on a computer-controlled traversing mechanism. The hot-wire surveys provided distributions of all three components of mean velocity and turbulent normal stresses as well as two components of Reynolds shear stress. From the mean velocity distribution on the $y-z$ plane the streamwise component of vorticity was calculated. These data were acquired in a 20 - by 30 -in. Low-Speed Wind Tunnel at NASA Glenn Research Center. The measurements were taken at a flow velocity of $29 \mathrm{ft} / \mathrm{sec}$, giving a Reynolds number in terms of the VG width of 17,500.

The ramp width, chord length, and height, were held fixed at $w=1.16$ in., $c=1.435$ in., and $h=$ 0.561 in., respectively. The thickness of the approach boundary layer normalized by the ramp width was $\delta / w=0.66$; the corresponding momentum thickness was $\delta_{2} / w=0.08$. In terms of the VG height, the boundary layer is 36 percent taller than the ramps, and the momentum thickness is 17 percent of the VG height. The boundary layer shape factor of 1.46 confirmed that the flow was turbulent.

The spacing between the ramps, shown as $s$ in the top view of the VG array in Figure 1(a), was varied during the test, with measurements taken for $s / w=0,0.25,0.5$, and 1.0. (Note that the spacing is defined on the basis of the distance between the extrema of the adjacent VGs.) Hot-wire surveys were carried out at axial positions of $x / w=0.108,1.0,2.0,4.0,8.0$, and 12.0. Baseline measurements without the ramps were also done for each of the axial locations listed in order to assess the impact of the VG array.

The spatial resolution for the hot-wire survey was first investigated. The spanwise step size in the survey was varied while keeping the vertical step size a constant. Velocity and vorticity contours measured at $x / w=1$ for three spanwise step sizes are shown in Figure 2. It can be seen that the distributions for the medium and fine step sizes look alike, while the coarse step size obviously fails to resolve the distribution. Based on these results the medium step size was considered adequate for this $x$-station. The step sizes and the extents of the survey fields were increased at the downstream locations approximately proportionate to the distance from the VG array. Note that the comparison of the distributions for parametric variations, at a given $\mathrm{x}$-station, was done with exactly the same spatial resolution. 


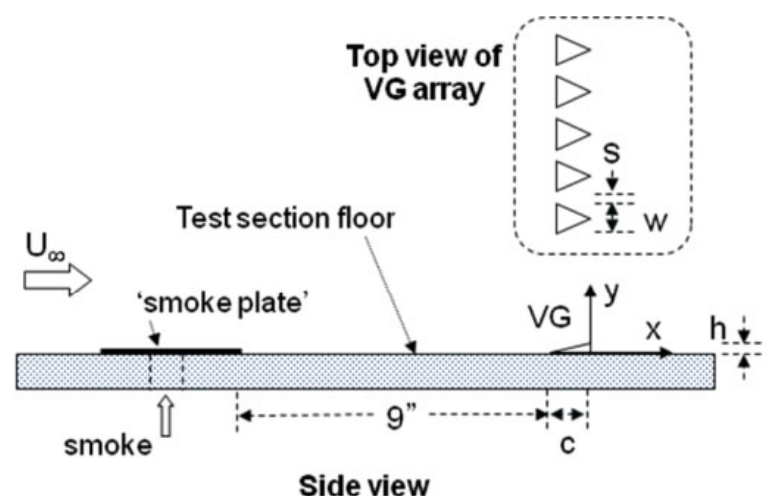

(a)

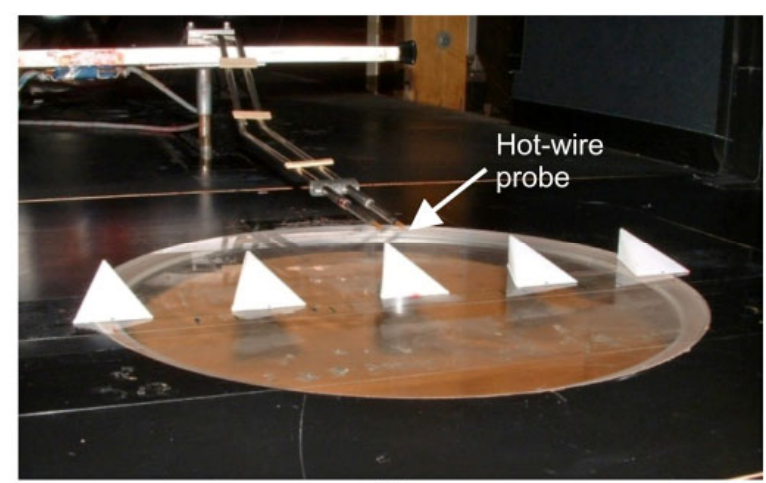

(b)

Figure 1.-Experimental setup. (a) A schematic showing the layout of the VGs in the test section and the location of the smoke plate; (b) a view of the VGs in the tunnel with the hot wire probes.
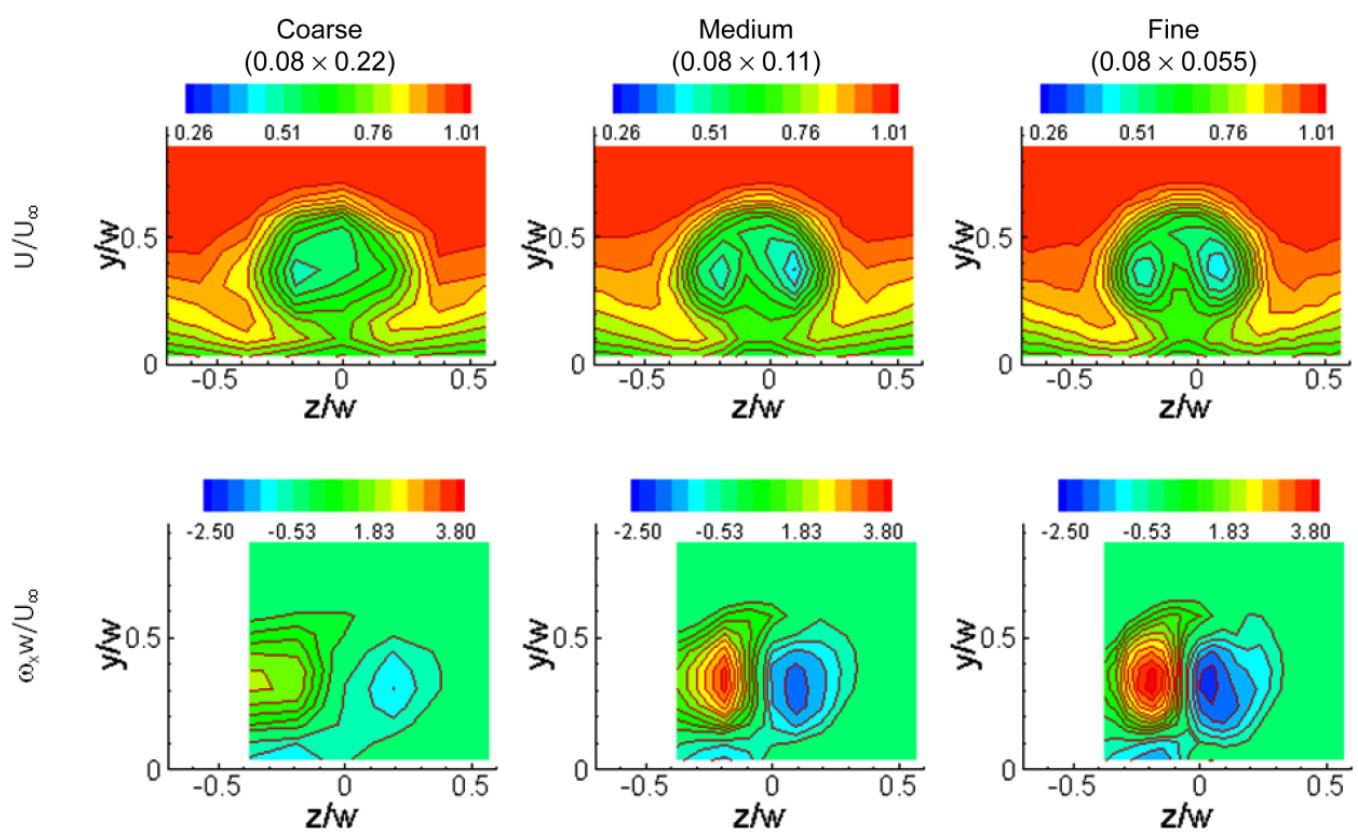

Figure 2.-Hot-wire survey results for varying spanwise step size with constant vertical step size (0.08 in.); velocity contours are shown in the top row and vorticity contours in the bottom row. 


\section{Results}

To obtain an initial assessment of the vertical extent of vortex penetration flow visualization was conducted. A sheet of smoke was introduced into the boundary layer and illuminated with a laser sheet at a given streamwise location. The visualization was done at each of the axial measurement planes (§II). Figure 3 shows sample smoke flow visualization results. Looking at the results in the middle row, one can see the greater distance between the vortices as the spacing $s$ is increased. The images in the column are for varying axial measurement location for a given spacing. The farther from the devices the laser sheet is introduced, the more diffuse the smoke is, though even at the station farthest downstream, the vortices can still be seen clearly.

The normalized mean velocity, turbulence intensity, and streamwise vorticity contours at $x / w=1$ downstream of a single VG are shown in Figure 4. The vorticity profile clearly shows the pair of counterrotating vortices generated by the ramp. In the mean velocity profile on the left, the streamwise velocity deficit created by the vortex pair is captured by blue contours. The streamwise vortex pair is embedded in this deficit region. The beneficial effect occurs on either side of this region where the high momentum freestream fluid is drawn in. This is manifested by the bending of the yellow and orange contour lines closer to the wall. An increase in turbulence intensity is observed in the entire deficit region especially in the cores of the two vortices.

As stated before, the interaction between the VGs was studied for four different spacings. The mean velocity contours for spacing $s / w=0.25$ are shown in Figure 5, as an example. At the first axial station, $x / w=0.108$, the developing vortex pair has a kidney shaped profile. Similar to the single VG case, the velocity contours along the edge of the vortex pair are pulled towards the wall. The boundary layer thinning between the vortex pairs is the greatest near the vortices and less in between. By the $x / w=1.0$ station, the vortex pair (i.e., the velocity deficit region) has become more round, and the boundary layer between the vortices has become more uniform. At the stations $x / w=2.0$ and 4.0 these trends continue, and there is a region of uniform boundary layer thinning between the vortex pairs. Also, the vortices have grown squeezing the region of uniform boundary layer in between. By the $x / w=8.0$ station, the growing vortices have begun to merge. The merging of the vortex pairs removes the region of benefit in between, and by $x / w=12.0$, the merged vortex pairs begin to look like a uniform thick boundary layer.

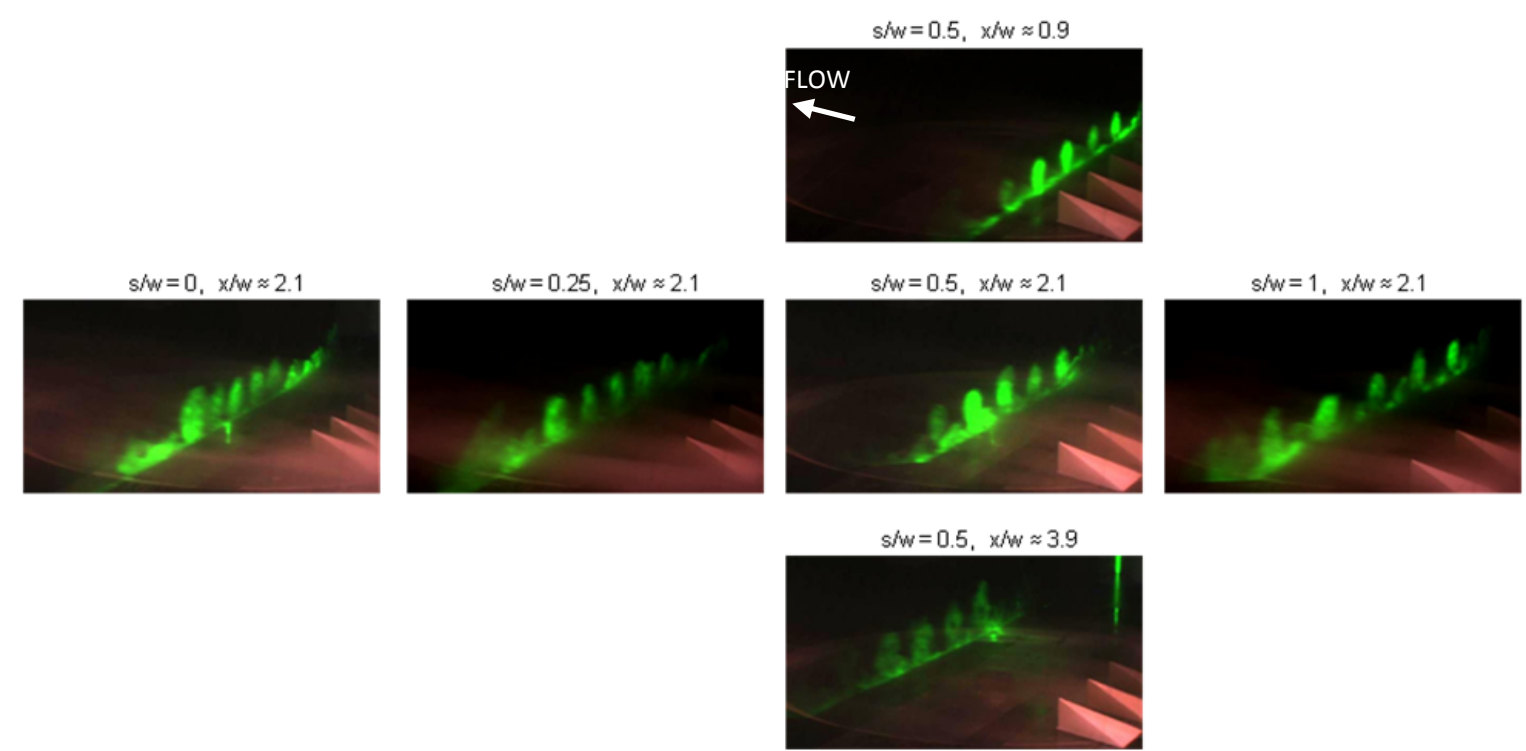

Figure 3.-Sample smoke flow visualization results with ramp spacing increasing from left to right in the middle row and axial position increasing from top to bottom in the column. 

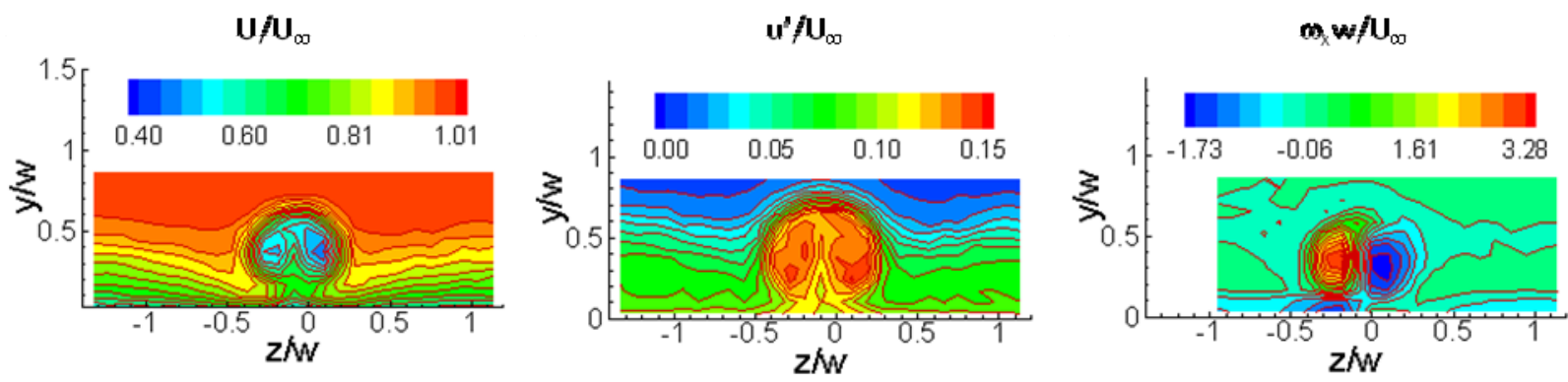

Figure 4.-Flowfield for a single VG at $x / W=1$ showing the normalized mean velocity, turbulence intensity, and streamwise vorticity contours.
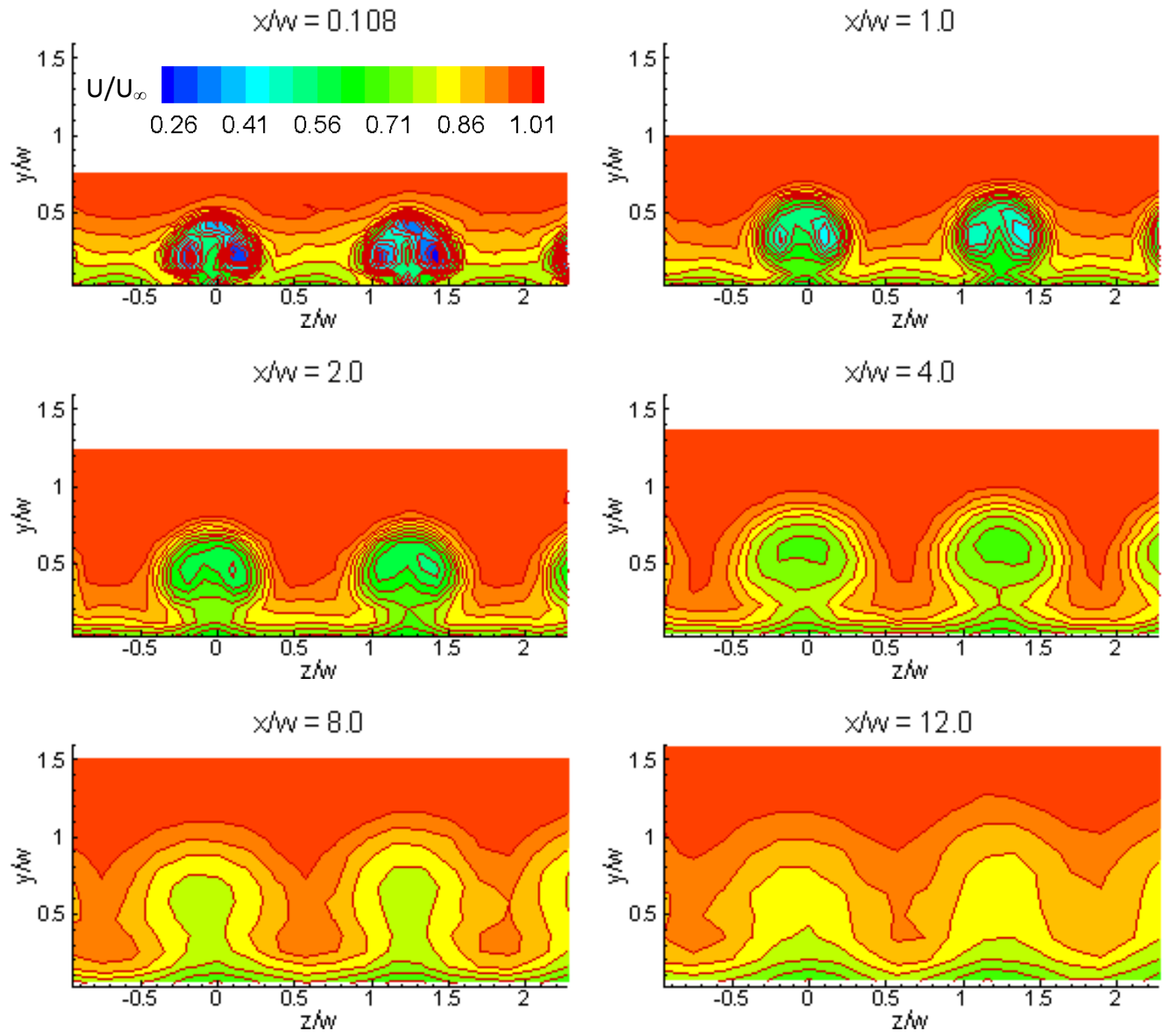

Figure 5.-Velocity contours showing the evolution of the vortices for $s / w=0.25$. 
The corresponding velocity distributions were also measured without the VG arrays. Another way to look at these data that clarify the effects of the ramps is to look at the contours of changes in the velocity, $\Delta U$. These contours are calculated by subtracting the velocities measured without VGs from the velocities measured with the VGs. The contours of $\Delta U$ are shown in Figure 6 for spacing $s / w=0$. Orange and red contours indicate positive values, or an increase in velocity; green and blue contours with dashed lines indicate negative values. At $x / w=0.108$, the increased velocity is evident near the wall in between the vortices. At $x / w=1$ and 2, the region of increased velocity is larger, and has begun to spread into the area beneath the vortices. At $x / w=4$, the growing vortices are just beginning to merge, and the regions of increased velocity are beginning to decrease in size. By $x / w=8$, the vortices have fully merged and there is little remaining benefit in terms of increased velocity near the wall.
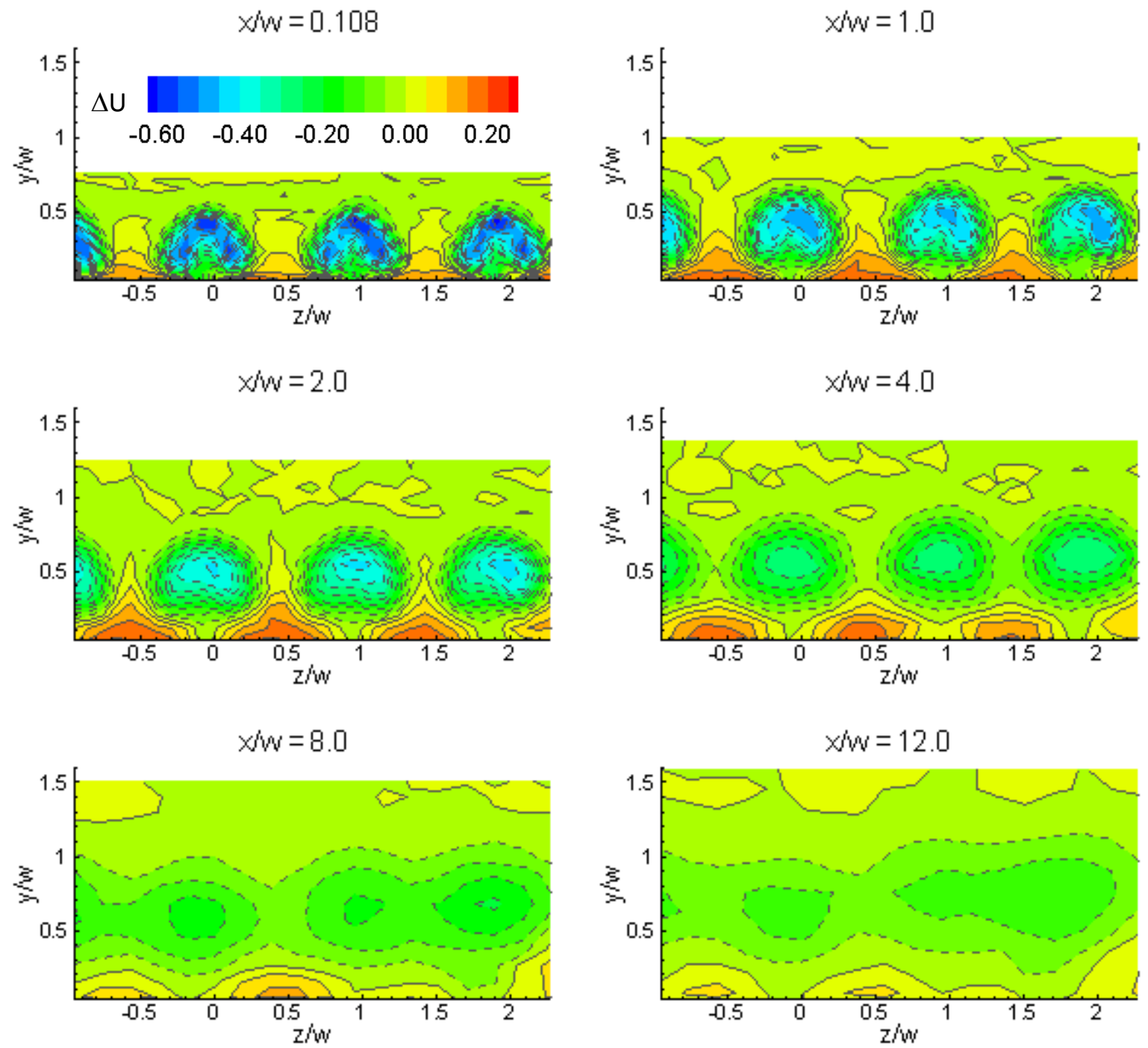

Figure 6.-Contours showing the evolution of the velocity difference $\Delta U$ for $s / W=0.0$. 
The contours of change in velocity for spacing $s / w=0.25$ are shown in Figure 7 . At $x / w=0.108$, the largest increase in velocity is measured at the foot of the vortex pair with a region of moderately increased velocity in between. At $x / w=1$ and 2, the interaction of the vortices spreads the region of increased velocity. At $x / w=4$ and farther downstream, the regions of increased velocity spread more and the spanwise variations near the wall become more uniform.
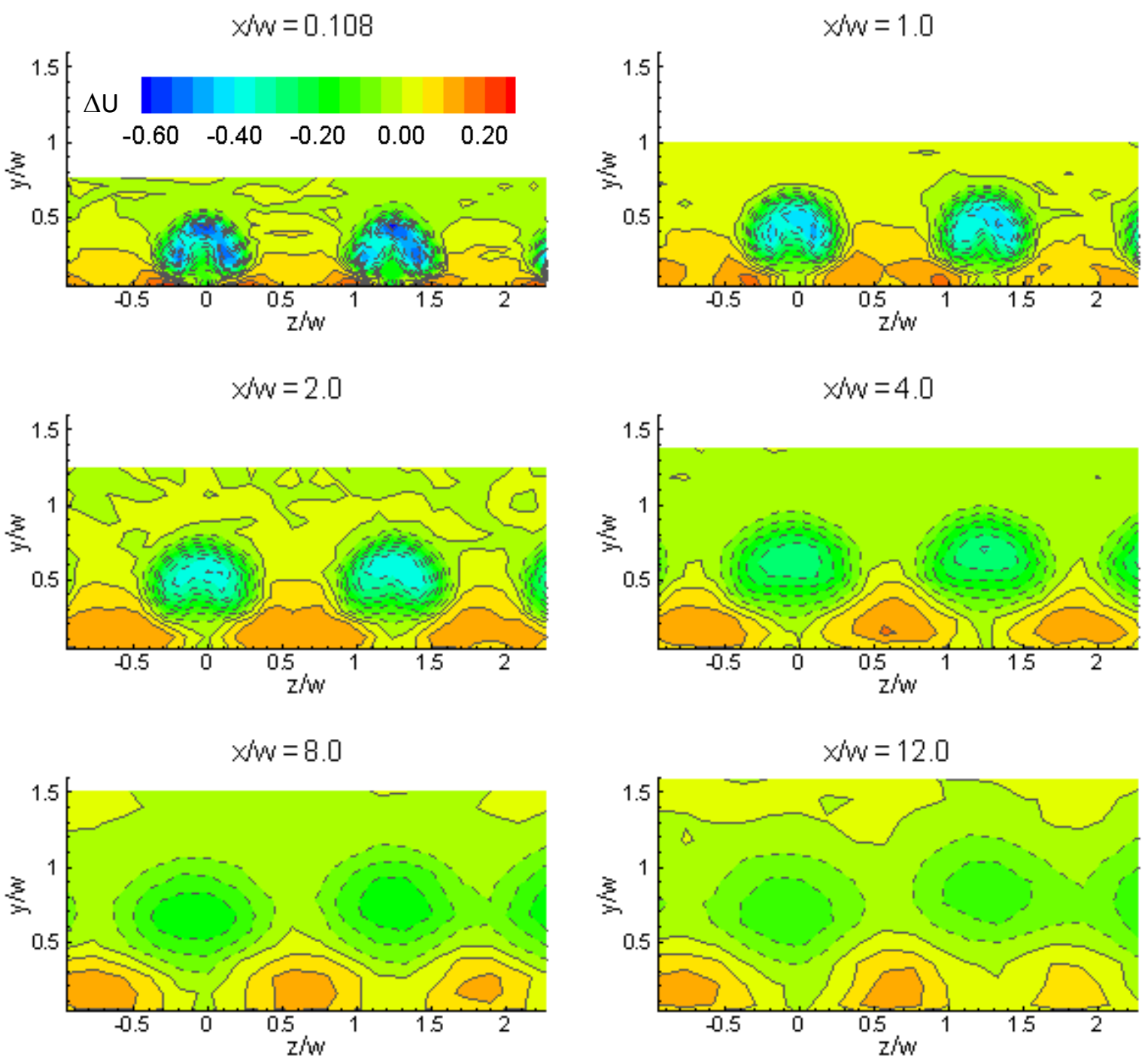

Figure 7.-Contours showing the evolution of the velocity difference $\Delta U$ for $s / w=0.25$. 
The contours of change in velocity are shown similarly in Figure 8 for spacing $s / w=0.5$. At $x / w=0.108$, a large increase in velocity is still seen at the foot of the vortex pair; however, the effect does not extend across the entire span between the vortex pairs. At station $x / w=1$, the increased velocity due to the vortices has spread. This trend continues until at $x / w=2.0$ the increased velocity regions have merged essentially into one region. At $x / w=4$ and farther downstream, a similar trend is noted as seen in Figure 7.
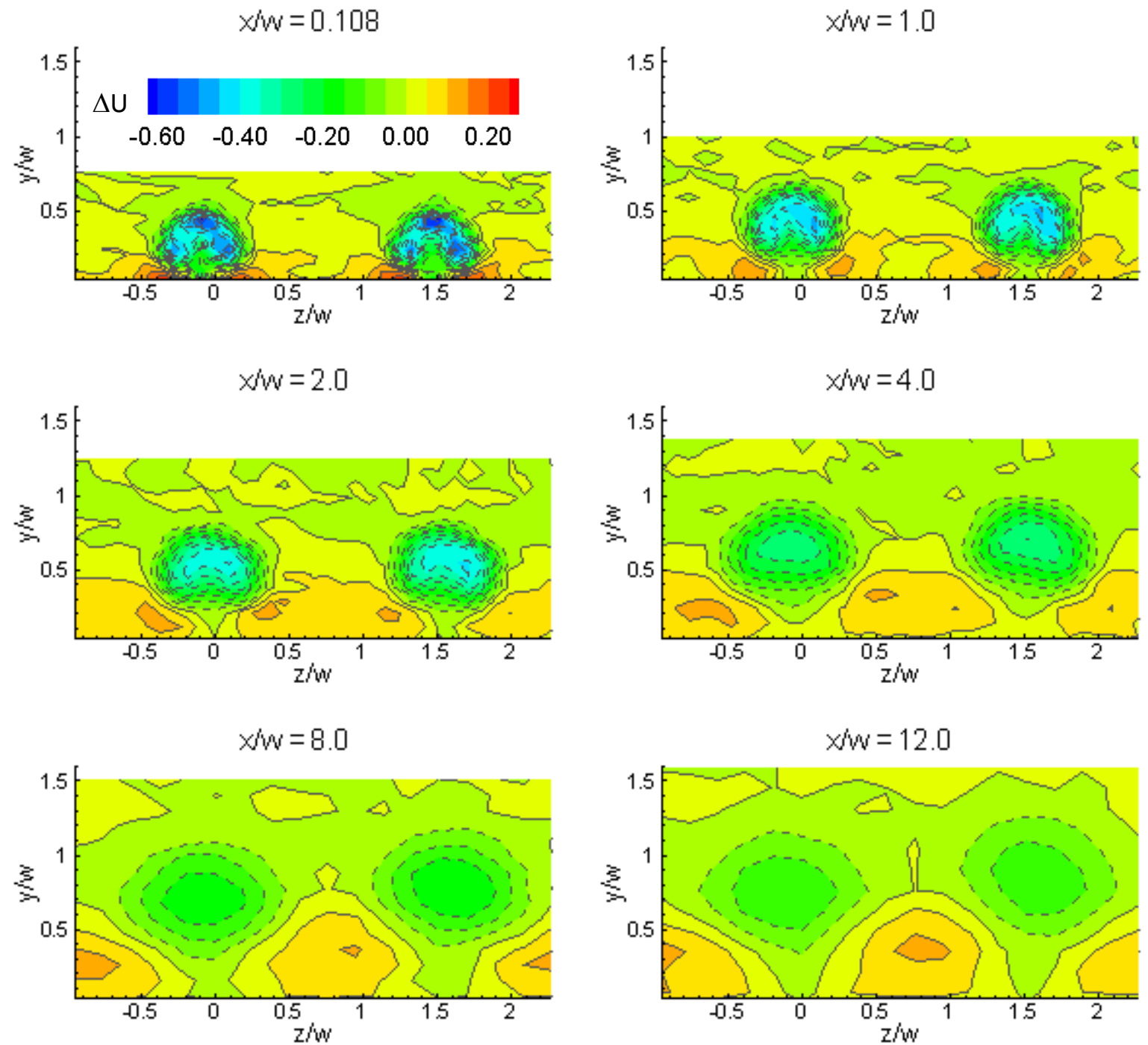

Figure 8.-Contours showing the evolution of the velocity difference $\Delta U$ for $s / W=0.5$. 
The contours of change in velocity for spacing $s / w=1.0$ are shown in Figure 9. At $x / w=0.108$, the contours look similar to data at corresponding station in Figure 8. It is apparent that these distributions are nearly the same as what would be obtained for an isolated ramp. For this large spacing, the vortex pairs evolve nearly independently, and the regions of increased velocity do not merge until $x / w=8.0$.
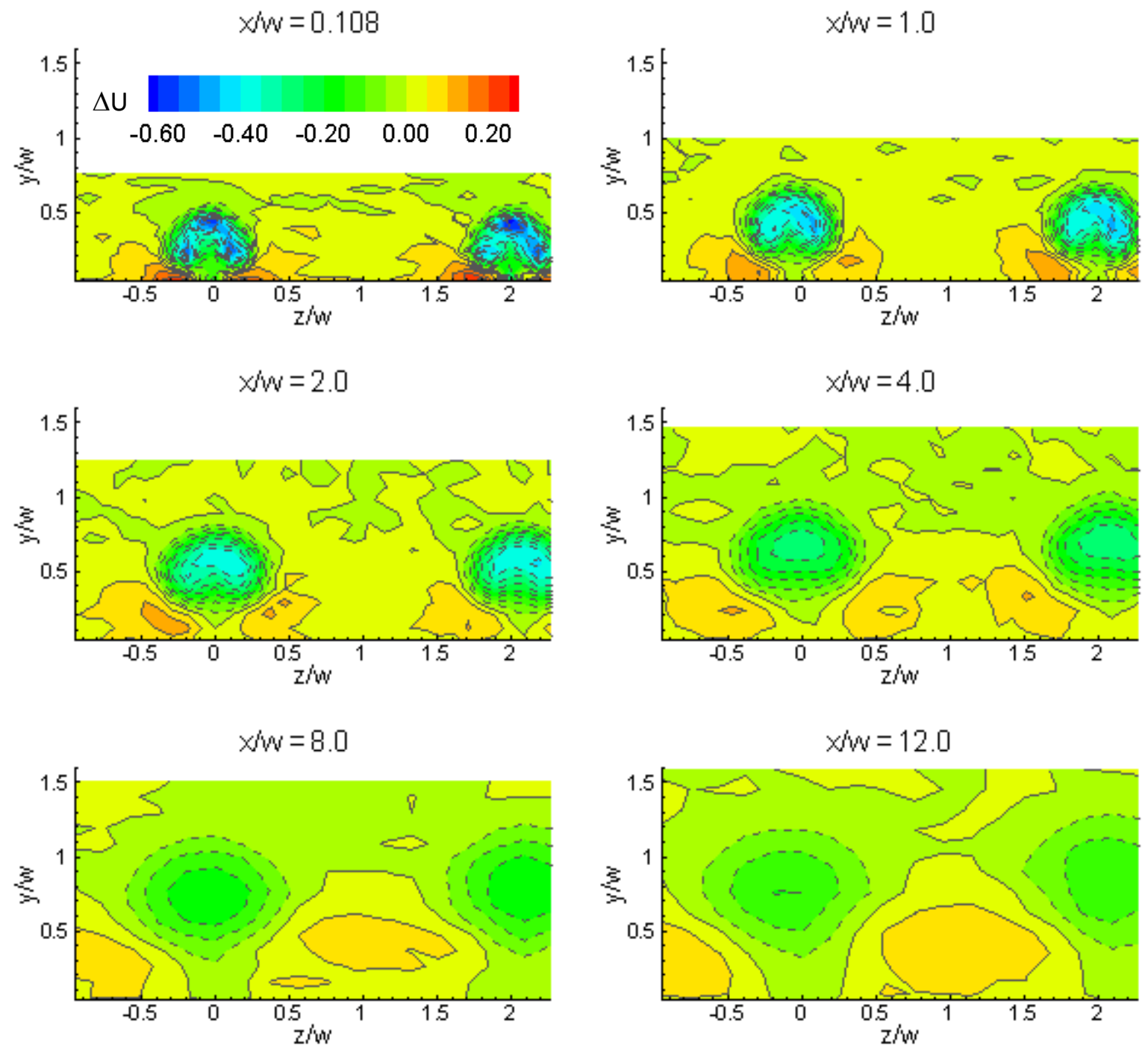

Figure 9.-Contours showing the evolution of the velocity difference $\Delta U$ for $s / W=1.0$. 


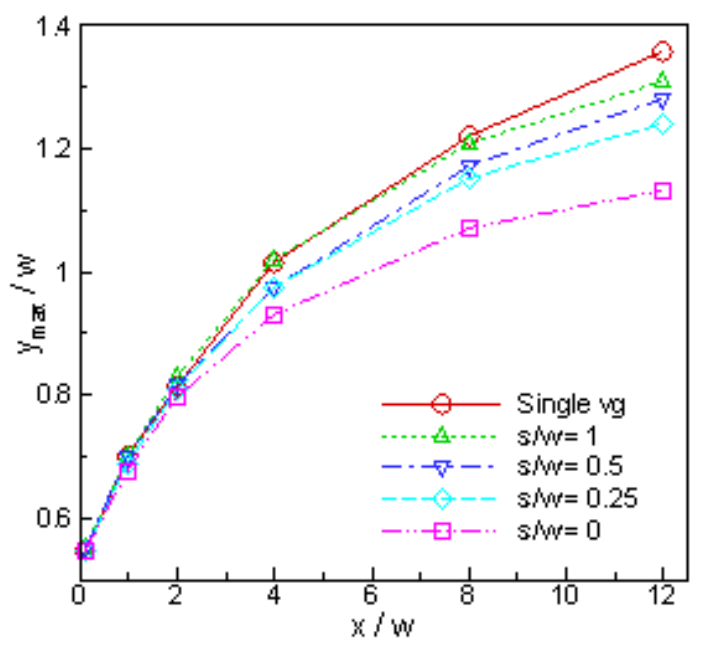

(a)

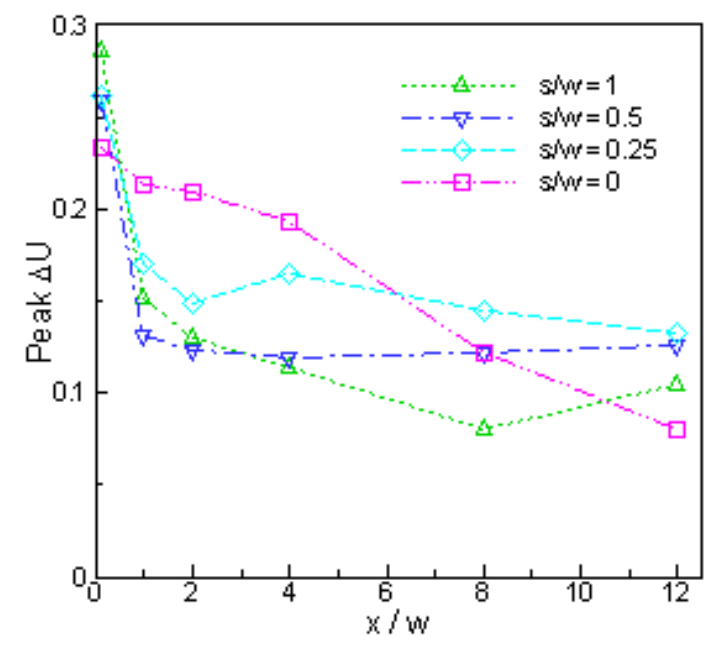

(c)

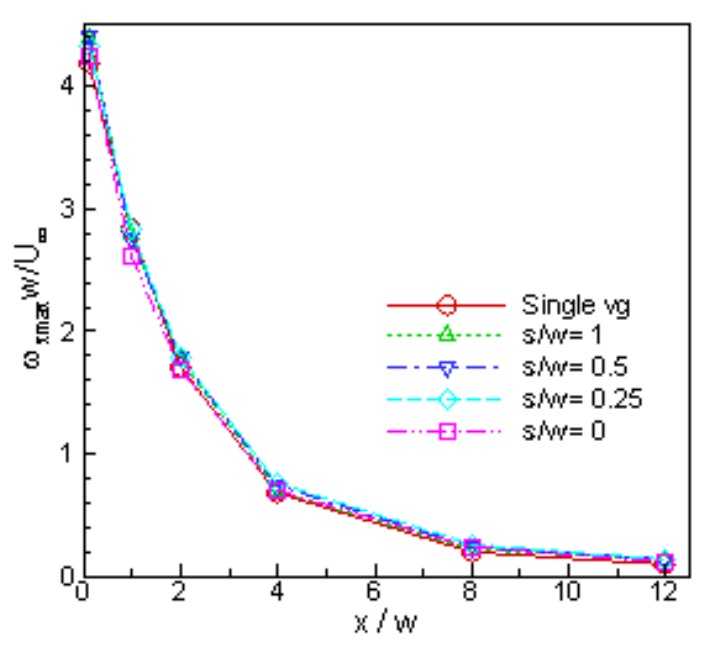

(b)

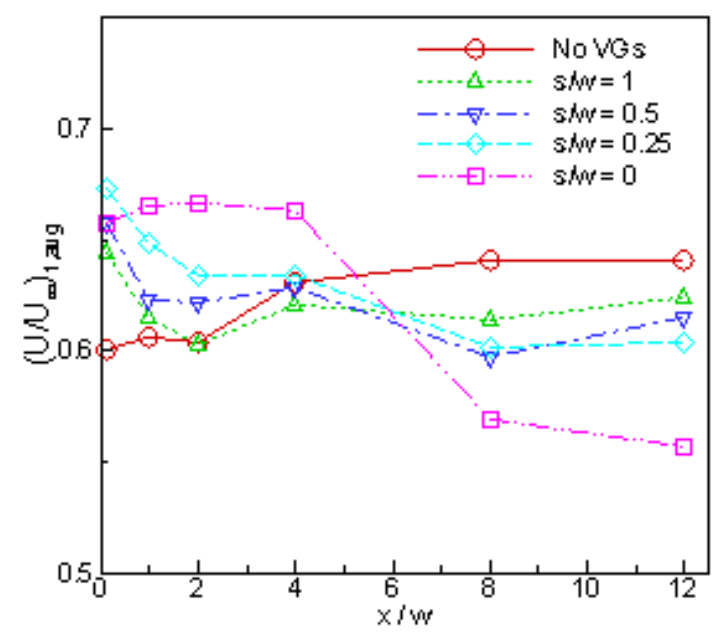

(d)

Figure 10.-Comparison of (a) vortex penetration, (b) peak streamwise vorticity, (c) peak $\Delta U$ for varying ramp spacing, and (d) span-averaged normalized streamwise velocity at the point nearest the wall.

Quantitative measures of the overall flow properties obtained from the surveys are discussed in the following. Figure 10 shows these results as a function of streamwise distance. Figure 10(a) shows vortex penetration, $y_{\max }$, defined as the value of $y$ where the velocity within the center of the deficit region has recovered to nearly the freestream value. For all VG spacings, the penetration increases with distance as expected. Also evident is that the smaller the device spacing is, the less the vortex pairs penetrate into the flow. For spacing $s / w=1$, the vortex penetration does not deviate from that measured for a single VG until $x / w=12.0$. This suggests that neighboring vortices do not influence each other until about that station. For closer spacings, the influence of a neighboring VG is seen farther upstream.

The decrease in vortex penetration with smaller VG spacing could be either due to decreased vortex strength or induction from neighboring pairs. Looking at Figure 10(b) we can see that there is little change in peak vorticity (i.e., vortex strength) regardless of VG spacing. Only for $s / w=0$ a marginal decrease in the strength is observed. This leaves one with the inference that the decreased penetration with reduced VG spacing is due to the other factor, namely induction from neighboring pairs.

Figure $10(\mathrm{c})$ is a plot of the maximum in the change in velocity $\Delta U$ for a given measurement station. This is shown as function of the streamwise distance. At the measurement plane closest to the VGs, $x / w=0.108$, the maximum occurs for the maximum spacing. Conversely, the smallest $\Delta U$ is measured for 
$s / w=0$. However, for all of the cases except $s / w=0$, the peak value falls off rapidly. At $x / w=1.0,2.0$, and 4.0 planes $s / w=0$ yields the largest velocity augmentation. Farther downstream at $x / w=8.0$ and 12.0, the spacing $s / w=0.25$ has the largest augmentation.

To determine whether these velocity augmentations were likely to result in a net benefit to the flowfield rather than an isolated region of increased velocity, the span-averaged normalized streamwise velocity at the first point off the wall was calculated. These values are shown in Figure 10(d) compared to the case of a turbulent boundary layer without VGs. The span-averaged near wall velocity for the no-VG case increases with axial position because the growth in the survey step size increased the distance of the first measurement point from the wall. At each axial station, the y-value of the first point in the profile is constant for all spacings. For axial positions up to $x / w=4$ increases in the span-averaged near wall velocity can be seen in the VG cases. At $x / w=8$ and 12 , the highest measured span-averaged streamwise velocity was for the case with no VGs. The smaller the spacing, the greater the span-averaged near wall velocity, and the further downstream the velocity shows an increase over the no-VG case. The sharp drop off in near wall velocity for $s / w=0$ is due to the vortices having fully merged.

\section{Conclusions}

Knowing that vortex generators increase the resistance to boundary layer separation by increasing the near wall velocity, the results presented here suggest that a range of optimal streamwise positions of the ramps can be determined. The VGs should be located at a streamwise location relative to the region that needs to be controlled where the VGs affect the entire span (i.e., the increased velocity regions from adjacent vortex pairs have merged) but not so far upstream of the control region that the velocity deficit regions have merged. This means smaller devices need to be closer axially to the expected separation region than larger ramps. For the ramp geometries and spacings tested in the present study for example, a ramp array with spacing $s / w=0$ would be optimally located between $x / w=1.0$ and $x / w=4.0$, over which range this spacing also produces the greatest average near wall velocity and the peak velocity augmentations. The resulting vortex pairs from ramp arrays with smaller spacing are seen to remain closer to the wall. Since the measured peak vorticity is nearly constant with spacing, it is inferred that induction due to neighboring vortex pairs is reducing vortex liftoff.

\section{References}

1. Lin, J.C., "Review of Research on Low-Profile Vortex Generators to Control Boundary-Layer Separation," Progress in Aerospace Sciences, 2002.

2. Ford, C.W.P. and Babinsky, H., "Micro-Ramp Control of Oblique Shock Wave/Boundary Layer Interactions," AIAA Paper 2007-4115, 37th Fluid Dynamics Conf., June 25-28, Miami, FL.

3. Lee, S., Loth, E. and Babinsky, H., "Normal Shock Boundary Layer Interaction Control Using MicroVortex Generators," AIAA Paper 2010-4254, $5^{\text {th }}$ Flow Control Conference, June 28-1, Chicago, IL.

4. Farokhi, S., "Smart Flow Control in Aircraft Engine Components \& Component Interactions," RTO AVT Symposium on "Design Principles and Methods for Aircraft Gas Turbine Engines," May 11-15, 1998, Toulouse, France.

5. Hirt, S.M., Chima, R.V., Vyas, M.A., Wayman, T.R., Conners, T.R., and Reger, R.W., "Experimental Investigation of a Large-Scale Low-Boom Inlet Concept," AIAA Paper 2011-3796, 29th AIAA Applied Aerodynamics Conference, June 27-30, Honolulu, HI.

6. Hirt, S.M. and Anderson, B.H., "Experimental Investigation of the Application of Microramp Flow Control to an Oblique Shock Interaction," AIAA Paper 2009-919, 47th Aerospace Sciences Meeting, January 5-8, Orlando, FL.

7. Milanovic, I.M. and Zaman, K.B.M.Q., "Fluid dynamics of highly inclined jets in crossflow," AIAA J., 42(5), pp. 874-882., 2004. 


\begin{tabular}{|c|c|c|c|c|c|}
\hline \multicolumn{5}{|c|}{ REPORT DOCUMENTATION PAGE } & $\begin{array}{l}\text { Form Approved } \\
\text { OMB No. 0704-0188 }\end{array}$ \\
\hline \multicolumn{6}{|c|}{$\begin{array}{l}\text { The public reporting burden for this collection of information is estimated to average } 1 \text { hour per response, including the time for reviewing instructions, searching existing data sources, gathering and maintaining the } \\
\text { data needed, and completing and revieving the collection of information. Send comments regarding this burden estimate or any other aspect of this collection of information, including suggestions for reducing this } \\
\text { burden, to Department of Defense, Washington Headquarters Services, Directorate for Information Operations and Reports ( } 0704-0188,1215 \text { Jefferson Davis Highway, Suite } 1204, \text { Arlington, VA } 22202-4302 \text {. } \\
\text { Respondents should be aware that notwithstanding any other provision of law, no person shall be subject to any penalty for failing to comply with a collection of information if it does not display a currently valid OME } \\
\text { control number. } \\
\text { PLEASE DO NOT RETURN YOUR FORM TO THE ABOVE ADDRESS. }\end{array}$} \\
\hline \multicolumn{2}{|c|}{$\begin{array}{l}\text { 1. REPORT DATE (DD-MM-YYYY) } \\
01-08-2012\end{array}$} & \multicolumn{3}{|c|}{$\begin{array}{l}\text { 2. REPORT TYPE } \\
\text { Technical Memorandum }\end{array}$} & 3. DATES COVERED (From - To) \\
\hline \multirow{3}{*}{\multicolumn{5}{|c|}{$\begin{array}{l}\text { 4. TITLE AND SUBTITLE } \\
\text { Experimental Study of Boundary Layer Flow Control Using an Array of Ramp-Shaped } \\
\text { Vortex Generators }\end{array}$}} & 5a. CONTRACT NUMBER \\
\hline & & & & & 5b. GRANT NUMBER \\
\hline & & & & & 5c. PROGRAM ELEMENT NUMBER \\
\hline \multirow{3}{*}{\multicolumn{5}{|c|}{$\begin{array}{l}\text { 6. AUTHOR(S) } \\
\text { Hirt, Stefanie, M.; Zaman, Khairul, B.M.Q. ; Bencic, Timothy, J. }\end{array}$}} & 5d. PROJECT NUMBER \\
\hline & & & & & 5e. TASK NUMBER \\
\hline & & & & & $\begin{array}{l}\text { 5f. WORK UNIT NUMBER } \\
\text { WBS 984754.02.07.03.13.02 }\end{array}$ \\
\hline \multicolumn{5}{|c|}{$\begin{array}{l}\text { 7. PERFORMING ORGANIZATION NAME(S) AND ADDRESS(ES) } \\
\text { National Aeronautics and Space Administration } \\
\text { John H. Glenn Research Center at Lewis Field } \\
\text { Cleveland, Ohio 44135-3191 }\end{array}$} & $\begin{array}{l}\text { 8. PERFORMING ORGANIZATION } \\
\text { REPORT NUMBER } \\
\text { E-18204 }\end{array}$ \\
\hline \multirow{2}{*}{\multicolumn{5}{|c|}{$\begin{array}{l}\text { 9. SPONSORING/MONITORING AGENCY NAME(S) AND ADDRESS(ES) } \\
\text { National Aeronautics and Space Administration } \\
\text { Washington, DC 20546-0001 }\end{array}$}} & $\begin{array}{l}\text { 10. SPONSORING/MONITOR'S } \\
\text { ACRONYM(S) } \\
\text { NASA }\end{array}$ \\
\hline & & & & & $\begin{array}{l}\text { 11. SPONSORING/MONITORING } \\
\text { REPORT NUMBER } \\
\text { NASA/TM-2012-217616 }\end{array}$ \\
\hline \multicolumn{6}{|c|}{$\begin{array}{l}\text { 12. DISTRIBUTION/AVAILABILITY STATEMENT } \\
\text { Unclassified-Unlimited } \\
\text { Subject Categories: } 02 \text { and } 34 \\
\text { Available electronically at http://www.sti.nasa.gov } \\
\text { This publication is available from the NASA Center for AeroSpace Information, 443-757-5802 }\end{array}$} \\
\hline \multicolumn{6}{|c|}{ 13. SUPPLEMENTARY NOTES } \\
\hline \multicolumn{6}{|c|}{$\begin{array}{l}\text { 14. ABSTRACT } \\
\text { The objective of this study was to obtain a database on the flowfield past an array of vortex generators (VGs) in a turbulent boundary layer. } \\
\text { All testing was carried out in a low speed wind tunnel with a flow velocity of } 29 \mathrm{ft} / \mathrm{sec} \text {, giving a Reynolds number of } 17,500 \text { based on the } \\
\text { width of the VG. The flowfield generated by an array of five ramp-shaped vortex generators was examined with hot wire anemometry and } \\
\text { smoke flow visualization. The magnitude and extent of the velocity increase near the wall, the penetration of the velocity deficit into the } \\
\text { core flow, and the peak streamwise vorticity are examined. Influence of various parameters on the effectiveness of the array is considered on } \\
\text { the basis of the ability to pull high momentum fluid into the near wall region. }\end{array}$} \\
\hline \multicolumn{6}{|c|}{$\begin{array}{l}\text { 15. SUBJECT TERMS } \\
\text { Vortex generators; Boundary layer flow }\end{array}$} \\
\hline \multicolumn{3}{|c|}{ 16. SECURITY CLASSIFICATION OF: } & $\begin{array}{l}\text { 17. LIMITATION OF } \\
\text { ABSTRACT }\end{array}$ & $\begin{array}{l}\text { 18. NUMBER } \\
\text { OF }\end{array}$ & $\begin{array}{l}\text { 19a. NAME OF RESPONSIBLE PERSON } \\
\text { STI Help Desk (email:help@sti.nasa.gov) }\end{array}$ \\
\hline $\begin{array}{l}\text { a. REPORT } \\
\text { U }\end{array}$ & $\begin{array}{l}\text { b. ABSTRACT } \\
\text { U }\end{array}$ & $\begin{array}{l}\text { c. THIS } \\
\text { PAGE } \\
\text { U }\end{array}$ & UU & $\begin{array}{c}\text { PAGES } \\
17\end{array}$ & $\begin{array}{l}\text { 19b. TELEPHONE NUMBER (include area code) } \\
443-757-5802\end{array}$ \\
\hline
\end{tabular}


